\title{
Cardiovascular Risks of Androgen Deprivation Therapy
}

\author{
Adriano Freitas Ribeiro, César Camara, Carlos Alexandre Segre, Miguel Srougi, Carlos V. Serrano Jr. \\ Instituto do Coração (InCor) e Divisão de Urologia² do Hospital das Clínicas da Faculdade de Medicina da Universidade de São Paulo, São \\ Paulo, SP - Brazil
}

\begin{abstract}
Prostate adenocarcinoma is the most common cancer type in the male sex after skin cancer. Among the several types of treatment for prostate cancer, the androgen deprivation therapy has been highly recommended in patients with metastatic or locally advanced disease, which probably results in increased survival. However, the androgen deprivation is the cause of several adverse effects. Complications such as osteoporosis, sexual dysfunction, gynecomastia, anemia and body composition alterations are well-known effects of the therapy. Recently, a number of metabolic complications have been described, such as increase in the abdominal circumference, insulin resistance, hyperglycemia, diabetes, dyslipidemia and metabolic syndrome, with a consequent increase in the risk of coronary events and cardiovascular mortality in this specific population.

This update article presents a literature review carried out at MEDLINE database of all literature published in English from 1966 to June 2009, using the following key words: androgen deprivation therapy, androgen suppression therapy, hormone treatment, prostate cancer, metabolic syndrome and cardiovascular disease, with the objective of analyzing which would be the actual cardiovascular risks of androgen deprivation therapy, also called androgen suppression, in patients with prostate cancer.
\end{abstract}

\section{Epidemiological aspects of prostate cancer}

Prostate adenocarcinoma, with the exception of skin cancer, presents the highest incidence among all cancer types diagnosed in the male sex in the USA, with more than 218,000 new cases diagnosed in the year 2007, corresponding to $29 \%$ of all neoplasias ${ }^{1}$. In Brazil, the estimated incidence for 2008 corresponds to 52 new cases for every 100,000 male individuals, with an approximate total number of 50,000 new cases diagnosed a year ${ }^{2}$. This incidence has been progressively

\section{Key words}

Cardiovascular diseases; risk; androgens/deficiency; endocrine system diseases; hormones/deficiency.

Mailing address: Carlos V. Serrano Jr. •

Av. Enéas Carvalho de Aguiar - Bloco II, 2 Andar, Sala 12 - 05403-000 - São Paulo, SP - Brazil

E-mail: carlos.serrano@incor.usp.br

Manuscript received August $6^{\text {th }}, 2009$; revised manuscript received March

15, 2010; accepted April 27, 2010. increasing in the last years, a fact attributed mainly to the routine measurement of the prostate-specific antigen (PSA) in males aged 45 years and older. This type of cancer presents the highest correlation with age and it is believed, in the USA, that one in every six men will be diagnosed with prostate cancer in his lifetime ${ }^{3}$.

In spite of the high incidence, the mortality rates are relatively low, with a projected number of deaths of little more than 27,000 in the USA in the year 2007, corresponding to $9 \%$ of the total number of cancer-related deaths. Approximately $86 \%$ of the diagnoses are attained when the disease is still localized and the disease-free five-year survival rate is close to $100 \%{ }^{4}$.

\section{Prostate cancer treatment: attention to androgen deprivation}

Regarding the treatment, prostate cancer presents several therapeutic possibilities, such as radiotherapy/brachytherapy, prostatectomy, androgen deprivation therapy and even an expectant conduct in special situations, depending on the clinical stage of the disease, tumor aggressiveness assessment, the presence of comorbidities and the patient's life expectancy.

Androgen deprivation therapy was first used by Huggins and Hodges in $1941^{5}$. Its effect is based on the fact that the prostatic neoplastic cells present a large number of androgen receptors on their surface and that their growth depends on the stimulation of these receptors. In brief, we can affirm that testosterone is the main circulating androgen and most of it is produced by Leydig cells in the testes, after central stimulation by the gonadotropin-releasing hormone $(\mathrm{GnRH})$ and the luteinizing hormone $(\mathrm{LH})$, which are secreted by the hypothalamus and the pituitary, respectively. After entering the prostate, testosterone is converted by $5 \alpha$-reductase into dihydrotestosterone and binds to a cytoplasmic receptor, forming a complex that modulates the nuclear transcription and consequently, all cell activity ${ }^{6}$. The figure below illustrates this hormonal axis and the specific mediations used to block it (Figure 1).

The androgen deprivation can be attained through $\mathrm{GnRH}$ agonists, steroidal and nonsteroidal antiandrogens, estrogens or bilateral orchiectomy. This review will cover only $\mathrm{GnRH}$ agonists and orchiectomy, the modalities considered to be the most efficient ones. GnRH agonists such as leuprolide and goserelin result in a central deprivation of testosterone secretion by suppressing the physiological pulsatility of $\mathrm{GnRH}$ secretion, with a consequent negative regulation of the pituitary receptors and lower $\mathrm{LH}$ secretion. These are long-acting medications administered by depot-injections. The orchiectomy is another form to inhibit androgen activity 


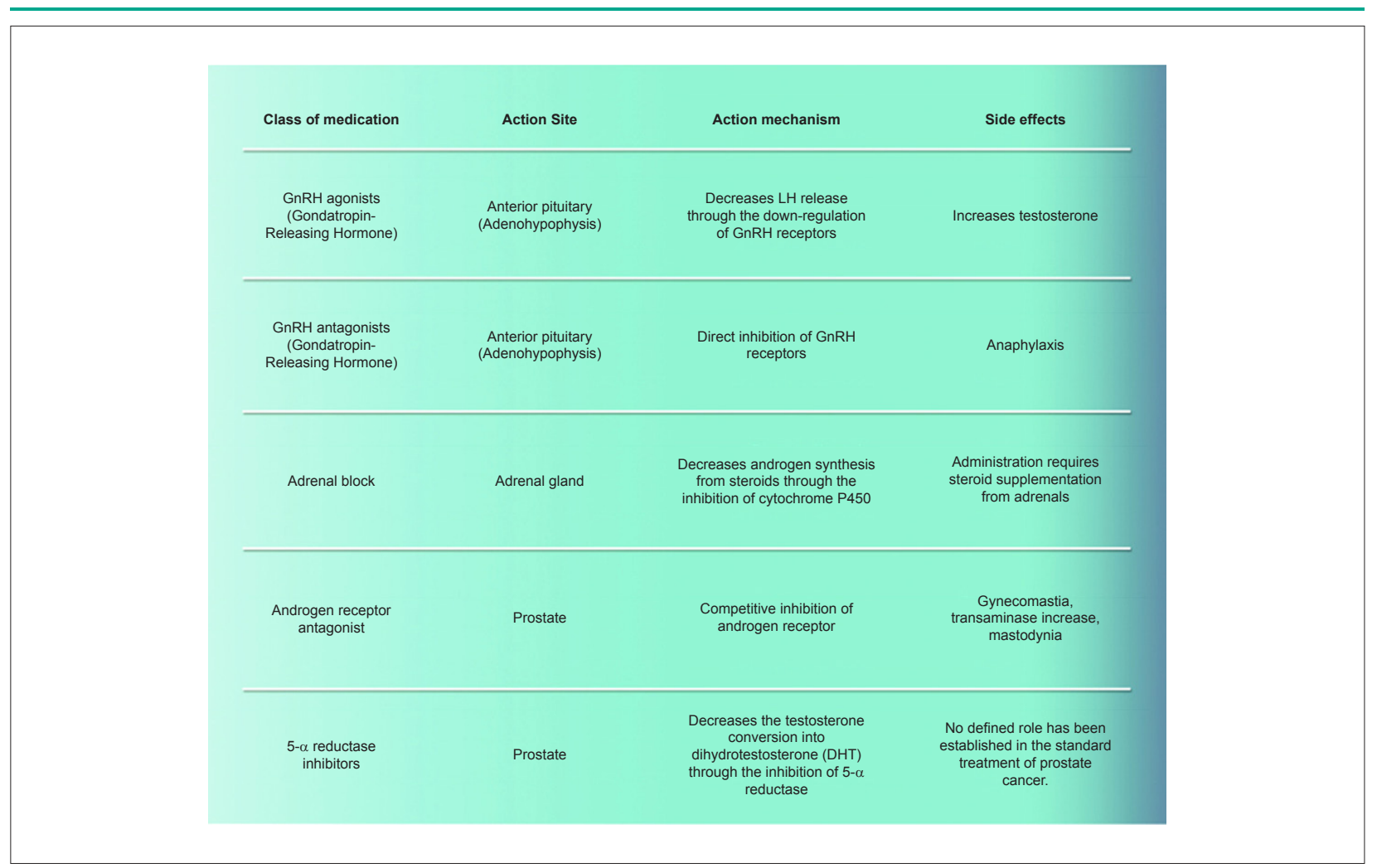

and is considered a relatively simple procedure with few risks; however, it is seldom used, due to the psychological effects on the patient ${ }^{7}$. The meta-analysis of ten studies did not show any difference in global survival, with similar mortality rates between the two therapeutic options ${ }^{8}$.

Initially, the deprivation was used only in patients with advanced (metastatic) disease, which has been shown to improve the individuals' quality of life, including the decrease in bone pain, pathological fractures, spinal cord compression and uretheral obstruction. More recently, studies have demonstrated an increase in survival in patients with localized advanced disease (extracapsular involvement or high-risk local disease -PSA $>20$, Gleason $>8$ or stage T2c) submitted to androgen deprivation after local treatment with radiotherapy or prostatectomy. It has also been indicated, although more controversially, for patients with PSA elevation after local treatment, even without evidence of metastatic disease $^{7}$. Therefore, the use of androgen deprivation therapy has increased considerably in the last decade.

\section{Adverse effects of androgen deprivation}

In spite of the benefits of the deprivation therapy and the very often dramatic and sustained responses presented by many patients, this type of treatment also exposes them to several adverse effects that have been long acknowledged, such as skeletal complications, loss of muscular strength, loss of libido, erectile dysfunction, hot flashes, anemia and gynecomastia. However, it was only in 1990, after a small cross-sectional study by Tayek et $\mathrm{al}^{9}$, that the first evidence of the deleterious cardiovascular effects of this type of treatment were disclosed. This study demonstrated, during a 12-month follow-up, the onset of metabolic and nutritional alterations that comprised increase in body weight, body fat and total cholesterol levels.

Several publications followed this first study ${ }^{10,11}$, with similar populations, which confirmed the weight gain, loss of lean mass, increase in body fat percentage, mainly at the cost of fat deposits in the subcutaneous tissue. Other studies have shown a decrease in arterial compliance ${ }^{14}$, as well as significant metabolic alterations ${ }^{11,12,13}$ : increase in the levels of total cholesterol, high-density lipoprotein (HDL-cholesterol), triglycerides, increase in insulin resistance and glycemia. The increase in the incidence of diabetes after the deprivation therapy has also been demonstrated ${ }^{14}$.

\section{Metabolic syndrome secondary to the hormonal deprivation}

In recent years, it has been demonstrated that hypogonadism is an independent risk factor for the development of metabolic syndrome $\mathrm{e}^{15,16}$ and that the androgen deprivation is nothing more than a model of hypogonadism that was purposely produced, either by surgery or drug-induced. Currently, this syndrome is defined as a set of multiple metabolic risk factors that are directly related to the development of atherosclerotic cardiovascular disease ${ }^{17}$.

The prevalence of metabolic syndrome ${ }^{18,19}$ after androgen deprivation was recently studied by Braga-Basaria et $\mathrm{a}^{20}$ They were the pioneers when they published a cross-sectional study 


\section{Review Article}

that demonstrated an increase in the prevalence of metabolic syndrome after one year of androgen deprivation $(22 \%$ in the group without deprivation vs 55\% in the group with deprivation, que demonstrou $p<0.03$ ). It is noteworthy the fact that the metabolic syndrome presented by patients submitted to androgen deprivation has some especial features that differ from the classically described form, such as the predominant accumulation of subcutaneous fat, rather than visceral fat accumulation and the concomitant increase in HDL-cholesterol and LDL-cholesterol levels. It is possible that the metabolic syndrome, as usually described, encompasses different patient profiles and that the alterations seen in patients submitted to androgen deprivation constitute a specific subgroup ${ }^{21}$. Moreover, the metabolic syndrome in these patients seems to develop early at the beginning of the treatment.

Aiming at the analysis of these metabolic alterations in the Brazilian population with prostate cancer, a preliminary joint study was carried out by Instituto do Coração (The Heart Institute) and the Division of Urology of Hospital das Clínicas of Faculdade de Medicina da Universidade de São Paulo, enrolling patients with a diagnosis of prostate cancer submitted to androgen deprivation. This was a prevalence study of 54 patients that were divided in two groups: recent deprivation (less than three months of treatment) and chronic deprivation (one year of treatment). The prevalence of metabolic syndrome in the recent deprivation group was $26 \%$, whereas the chronic deprivation group presented a prevalence of $48 \%$. Therefore, in our population, there is an increase in the prevalence of metabolic syndrome in patients submitted to androgen deprivation ${ }^{22,23}$.

\section{The interaction "androgen deprivation" vs metabolic syndrome vs cardiovascular disease in patients with prostate cancer}

Considering all the alterations, several doubts have surfaced regarding the safety and potential cardiovascular risks that are inherent to the deprivation therapy. Statistical data from the last decade already showed that cardiovascular diseases are the main cause of death in patients with prostate cancer submitted to hormonal deprivation and that these rates are higher than those found in the general population ${ }^{24}$. Recently, three studies that have been published, which will be analyzed next, have strongly suggested an increase in the cardiovascular mortality, as well as an increase in the frequency of nonfatal myocardial infarction (MI) in this population.

The first study, carried out by Keating et $\mathrm{al}^{25}$, was an observational study of population that comprised more than 73,000 patients with a diagnosis of localized prostate cancer. Of this total, $36 \%$ were submitted to hormonal deprivation with GnRH agonists and 6.9\% through orchiectomy. After a mean follow-up of 4.6 years, it was observed that the use of GnRH agonists was associated with a $44 \%$ increase in the risk of developing diabetes, $11 \%$ increase in the risk of myocardial infarction and $16 \%$ increase in the risk of sudden death. Orchiectomy, on the other hand, was associated with a $34 \%$ increase in the risk of developing diabetes and was not associated with an increase in the risk of cardiovascular diseases. Another study, published by Tsai et $\mathrm{a}^{26}$, analyzed more than
1,000 patients submitted to androgen deprivation and observed a cumulative five-year incidence of cardiovascular death of 5.5\% in those older than 65 years. This incidence was significantly lower for patients without deprivation, with a $2.0 \%$ risk for those older than 65 and 3.6\% for those younger than 65 years.

It is important to mention that these studies present limitations, mainly the fact that they are retrospective studies, and thus, lack the capacity to control other cardiovascular risk factors. Nevertheless, the difference in mortality between the groups is very significant and suggests a role of the deprivation in this difference.

The third and more recent study was published by D'Amico et $\mathrm{al}^{27}$, quewho analyzed the influence of the deprivation on the frequency and time of development of fatal MI. This study was carried out based on the combined retrospective analysis of the results of three randomized trials with androgen deprivation and radiotherapy, published in Australia, Canada and United States. An increase in the cumulative incidence of fatal MI was observed in patients older than 65 years that were submitted to deprivation, in comparison with those that were not submitted to deprivation. Patients that were submitted to only three months of deprivation therapy presented an incidence of $\mathrm{Ml}$ similar to that observed in those submitted to a six-month therapy, suggesting that a three-month treatment period is enough to cause deleterious cardiovascular effects. Moreover, the occurrence of fatal $\mathrm{MI}$ in patients submitted to deprivation had an earlier onset than in those without deprivation therapy.

\section{Conclusion}

In spite of the potential limitation of the present review that restricted the bibliography to the Medline database, it is increasingly evident that this modality of treatment results in several important side effects, such as diabetes, dyslipidemia, metabolic syndrome and coronary artery disease, including the increase in the rate of fatal infarctions and cardiovascular mortality. Therefore, although it is effective in the treatment of specific subgroups of patients with prostate cancer, the indication must always be judiciously made and individualized for each patient, aiming at minimizing the cardiologic impact as well as optimizing the oncologic benefit. It is also worth mentioning that these patients must be monitored by both the urologist and the cardiologist and must be routinely evaluated, with the objective of attaining the early diagnosis and treatment of the potentially adverse cardiovascular effects.

\section{Potential Conflict of Interest}

No potential conflict of interest relevant to this article was reported.

\section{Sources of Funding}

There were no external funding sources for this study.

\section{Study Association}

This study is not associated with any post-graduation program. 


\section{References}

1. Jemal A, Siegel R, Ward E, Murray T, Xu J, Thun MJ. Cancer statistics, 2007 CA Cancer J Clin. 2007; 57 (1): 43-66.

2. Ministério da Saúde. Instituto Nacional do Câncer (INCA). Estimativa 2008 / Incidência de câncer no Brasil. [Acesso em 2010 jan 10]. Disponível em http://www.inca.gov.br/conteudo_view.asp?id=1794.

3. Patrick C, Theodore L, Mario A. Localized prostate cancer. N Engl J Med. 2007; 357 (26): 2696-705.

4. Ries LAG, Eisner MP, Kosary CL. SEER Cancer Statistics Review, 1975-2000. Bethesda, MD: National Cancer Institute; 2003.

5. Huggins C, Hodges CV. Studies on prostate cancer: I. The effects of castration, of estrogen, and androgen injection on serum phosphatases in metatastic carcinoma of the prostate. Cancer Res. 1941; 1: 293-7.

6. Limonta P, Montagnani M, Moretti M. LHRH analogues as anticancer agents: pituitary and extrapituitary sites of action. Expert Opin Investig Drugs. 2001; 10 (4): 709-20.

7. Sharifi N, Gulley JL, Dahut WL. Androgen deprivation therapy for prostate cancer. Review. JAMA. 2005; 294 (2): 238-44.

8. Seidenfeld J, Samson DJ, Hasselblad V, Aronson N, Albertsen PC, Bennett CL, et al. Single-therapy androgen suppression in men with advanced prostate cancer: a systematic review and meta-analysis. Ann Intern Med. 2000; 132 (7): 566-77.

9. Tayek JA, Heber D, Byerley LO, Steiner B, Rajfer J, Swerdloff RS. Nutriciona and metabolic effects of gonadotropin-releasing hormone agonist treatment for prostate cancer. Metabolism. 1990; 39 (12): 1314-9

10. Basaria S, Lieb J 2nd, Tang AM Deweese T, Carducci M, Eisenberger MI, et al. Long-term effects of androgen deprivation therapy in prostate cancer patients. Clin Endocrinol (Oxf). 2002; 56 (6):779-86.

11. Smith MR, Finkelstein JS, McGovern FJ, Zietman AL, Fallon MA, Schoenfeld DA, et al. Changes in body composition during androgen deprivation therapy for prostate cancer. J Clin Endocrinol Metab. 2002; 87 (2): 599-603.

12. Braga-Basaria M, Muller DC, Carducci MA, Dobs AS, Basaria S. Hiperglycemia and insulin resistance in men with prostate carcinoma who receive androgen deprivation therapy. Cancer. 2006; 106 (3): 581-8.

13. Smith MR, Lee $H$, Nathan DM. Insulin sensitivity during combined androgen blockage for prostate cancer. J Clin Endocrinol Metab. 2006; 91 (4): 1305-8.

14. Smith JC, Bennett S, Evans LM, Kynaston HG, Parmar M, Mason MD, et al. The effects of induced hypogonadism on arterial stiffness, body composition, and metabolic parameters in males with prostate cancer. J Clin Endocrinol Metab. 2001; 86 (9): 4261-7.
15. Kalyani RR, Dobs AS. Androgen deficiency, diabetes, and the metabolic syndrome in men. Curr Opin Endocrinol Diabetes Obes. 2007; 14 (3) 226-34.

16. Makhsida N, Sha J, Yan G, Fisch H, Shabsigh R. Hypogonadism and metabolic syndrome: implications for testosterone therapy. J Urol. 2005; 174 (3): 827-34.

17. De Souza JA, Vindis C, Hansel B, Nègre-Salvayre A, Serrano Jr CV, et al. Metabolic syndrome features small, apolipoprotein A-I-poor, triglyceride-rich HDL3 particles with defective anti-apoptotic activity. Atherosclerosis. 2008; 197 (1): 84-94.

18. International Diabetes Federation: The IDF consensus worldwide definition of the metabolic syndrome. [Access in 2009 Dec 13]. Available from http:// www.idf.org/webdata/docs/Metabolic_syndrome_definition.pdf.

19. Sociedade Brasileira de Cardiologia. IV Diretriz brasileira sobre dislipidemias e prevenção da aterosclerose. Arq Bras Cardiol. 2007; 88 (supl 1): 1-19.

20. Braga-Basaria M, Dobs AS, Muller DC, Carducci MA, Majnu J, Egan J, et al Metabolic syndrome in men with prostate cancer undergoing long-term androgen-deprivation therapy. J Clin Oncol. 2004; 24 (24): 3979-83.

21. Smith MR. Androgen deprivation therapy for prostate cancer: new concepts and concerns. Curr Opin Endocrinol Diabetes Obes. 2007; 14 (3): 247-54.

22. Lee H, McGovern K, Finkelstein JS, Smith MR. Changes in bone mineral density and body composition during initial and long-term gonadotropinreleasing hormone agonist treatment for prostate carcinoma. Cancer. 2005; 104 (8):1633-7.

23. Lage MJ, Barber BL, Markus RA. Association between androgen-deprivation therapy and incidence of diabetes among males with prostate cancer Urology. 2007; 70 (6): 1104-8.

24. Brown BW, Brauner C, Minotte MC. Non-cancer deaths in white adult cancer patients. J Natl Cancer Inst. 1993; 85: 979-87.

25. Keating NL, O'Malley AJ, Smith MR. Diabetes and cardiovascular disease during androgen deprivation therapy for prostate cancer. J Clin Oncol. 2006; 24 (27): 4448-56.

26. Tsai HK, D'Amico AV, Sadetsky N, Chen MH, Carroll PR. Androgen deprivation therapy for localized prostate cancer and the risk of cardiovascular mortality. J Natl Cancer Inst. 2007; 99 (20): 1516-24.

27. D'Amico AV, Denham JW, Crook J, Chen MH, Goldhaber SZ, Lamb DS, et al. Influence of androgen suppression therapy for prostate cancer on the frequency and timing of fatal myocardial infarctions. J Clin Oncol. 2007; 25 (17): 2420-5. 